\title{
FORMAÇÃO DE REGENTES DE ENSINO PRIMÁRIO DO TERRITÓRIO FEDERAL DO GUAPORÉ: O CURSO NORMAL REGIONAL CARMELA DUTRA
}

\author{
Formation of primary school teachers in the Federal Territory of Guaporé: the \\ Normal Regional Course Carmela Dutra
}

\begin{abstract}
Formación de regentes de enseñanza primaria del Territorio Federal del Guaporé: el Curso Normal Regional Carmela Dutra
\end{abstract}

\author{
Marijâne Silveira da Silva *
}

\section{Resumo}

Este artigo traz algumas reflexões sobre a formação de regentes de ensino primário do Território Federal do Guaporé, tendo como lócus o Curso Normal Regional "Carmela Dutra", criado por meio do Decreto n. 47 de 19 de dezembro de 1947. Adota uma abordagem teórica com ênfase na história da educação, elegendo bibliografias da área com análise de documentos oficiais, obras memorialísticas e jornais da época. O recorte temporal delimitado compreende o ano inicial de criação do Curso, a instalação em 1948 e o ano de colação de grau dos formandos em 1951. Durante este período o Curso funcionava na capital, Porto Velho, em regime de internato feminino e externato misto, na modalidade de Ensino Normal no nível do primeiro ciclo, cuja finalidade era de formar regentes de ensino para atuação nas escolas primárias do Território. Para ingressar no Curso o discente deveria ter idade mínima de 13 anos, certificado de estudos primários completos (cinco anos) e ser aprovado em exame de admissão. A formação era realizada em quatro séries anuais e os programas das disciplinas seguiam as orientações expedidas pelo Ministério da educação e Saúde. Neste sentido, constata-se que o Curso Normal Regional do Território Federal do Guaporé atendia as prescrições nacionais estabelecidas pela Lei Orgânica do Ensino Normal, expedida pelo Decreto-lei n. ${ }^{\circ}$ 8.530, de 2 de janeiro de 1946.

PALAVRAS-CHAVE: Formação de regentes de ensino primário. Curso Normal Regional Carmela Dutra. Território Federal do Guaporé.

\begin{abstract}
This article brings some reflexions about the formation of primary school teachers in the Federal Territory of Guaporé and have as a locus the Normal Regional Course called Carmela

\footnotetext{
* Em pós-doutoramento no Programa de Pós-graduação em Educação da UFMT com financiamento da Capes. Professora Adjunta da Universidade Federal de Rondônia (UNIR). Pesquisa: História da Educação, com ênfase em Ensino Primário, Infância, Escolarização da infância, Imprensa e Impressos, Memória da Escola e formação docente. É coordenadora do GEPHERO - Grupo de Estudos e Pesquisa em História da Educação de Rondônia (UNIR). Endereço Institucional: BR 364, Km 9,5 - CEP: 76801059 - Porto Velho/RO. E-mail: mari.jane@unir.br. Resultado de pesquisa desenvolvida no âmbito da UNIR e registrado na Propesq sob Portaria 061/2018/PR, de 10 de set de 2018.
} 
Dutra that was created by Decree No. 47 of December 19, 1947. It adopts a technical approach with emphasis on the history of education, electing bibliographies of the area with analysis of official documents, memorial works and newspaper of the time. The delimited time frame comprises the initial year of creation of the course, the installation in 1948 and the year of graduation of graduates in 1951. During this period, the Normal Course Regional operated in the capital, Porto Velho, under a female boarding school and mixed boarding school in the form of Normal Education at the level of the first cycle, whose purpose was to train teaching conductors to work in the primary schools of the Federal Territory of Guaporé. To enter the course, the student must be at least 13 years old, complete primary school certificate (five years) and pass the admission exam. The training was carried out in four annual series and the programs of the disciplines followed the guidelines issued by the Ministry of Education and Health. In this sense, it appears that the Regional Normal Course of the Federal Territory of Guaporé met the national prescriptions established by the Organic Law of Education Normal, issued by Decree-Law n. ${ }^{\circ} 8.530$ of January 2, 1946.

KEYWORDS: Formation of primary school teachers. The Normal Regional Course Carmela Dutra. Federal Territory of Guaporé.

\section{Resumen}

Este artículo trae algunas reflexiones sobre la formación de regentes de enseñanza primaria del Territorio Federal del Guaporé, teniendo como loto el Curso Normal Regional "Carmela Dutra", creado por medio del Decreto n. 47 de 19 de diciembre de 1947. Adopta un enfoque teórico con énfasis en la historia de la educación, eligiendo bibliografías del área con análisis de documentos oficiales, obras conmemorativas y periódicos de la época. La línea temporal delimitada comprende el año inicial de creación del Curso, la instalación en 1948 y el año de graduación de los graduados en 1951. Durante este período el Curso funcionaba en la capital, Porto Velho, en régimen de internado femenino y externato mixto, en la modalidad de Enseñanza Normal en el nivel del primer ciclo, cuya finalidad era formar regentes de enseñanza para actuar en las escuelas primarias del Territorio. Para ingresar al Curso el alumno debería tener una edad mínima de 13 años, certificado de estudios primarios completos (cinco años) y ser aprobado en examen de admisión. La formación se realizaba en cuatro series anuales y los programas de las disciplinas seguían las orientaciones expedidas por el Ministerio de Educación y Salud. En este sentido, se constata que el Curso Normal Regional del Territorio Federal del Guaporé cumplía las prescripciones nacionales establecidas por la Ley Orgánica de la Enseñanza Normal, expedida por el Decreto-lei n. ${ }^{\circ} 8.530$, de 2 de enero de 1946.

PALABRAS CLAVE: Formación de regentes de enseñanza primaria. Curso Normal Regional Carmela Dutra. Territorio Federal del Guaporé.

\section{INTRODUÇÃO}

O Território Federal do Guaporé (atual Rondônia) foi criado pelo Decreto-lei n. 5.812, de 13 de setembro de 1943, com áreas desmembradas dos Estados do Amazonas e Mato Grosso ${ }^{1}$. Um mês após a sua criação, o presidente Getúlio Vargas nomeou Aluízio Ferreira como Governador.

\footnotetext{
${ }^{1}$ A transformação destas terras em Território foi articulada anos antes em um projeto de decreto-lei criado pela presidência da República em 1938, que previa a criação de alguns Territórios Federais (HUGO, 1995).
} 
No início, o Território foi dividido em quatro municípios, mas, em 1945 passou a ser constituído somente pelos municípios de Porto Velho e Guajará-Mirim, sendo Porto Velho, que na ocasião contava "(...) uns três mil habitantes dos quais 2 mil ligados à Estrada de Ferro Madeira-Mamoré" (HUGO, 1995, p.51) escolhido para ser a sede da administração executiva (a capital), por se destacar nas questões econômicas, populacional, geográficas, políticas, entre outras.

Essas duas cidades foram se estruturando com recursos oriundos do Governo Federal, com pessoas que migravam de outros estados brasileiros para atender às necessidades funcionais, bem como atraídas pelas campanhas de colonização acentuadas pela descoberta da cassiterita e pela construção de uma rodovia que interligasse Porto Velho a Cuiabá, possibilitando o trânsito de pessoas e mercadorias entre as regiões Norte e Centro Oeste.

As mudanças ocorridas no espaço geográfico, político, e populacional impactaram diretamente a área educacional, com a criação do Departamento de Educação $^{2}$ pelo Decreto Territorial $n^{\circ}$. 13, de 10 de abril de 1944, sendo responsável pela organização e administração do sistema escolar do Território, que contava com 27 unidades escolares, das quais 17 estavam localizadas em Porto Velho ${ }^{3}$.

Ao discorrer sobre a situação do ensino em Porto Velho, o professor Enos Eduardo Lins, diretor interino da Divisão de Educação do Guaporé em 1947, chama a atenção para a carência que havia na área educacional, principalmente relativa a insuficiência de professores habilitados para atender às escolas primárias:

\begin{abstract}
Inegavelmente o ensino deixa muito a desejar ainda em P. Velho. Porque nos faltam elementos. Porque não dispomos dos meios indispensáveis a uma modelar organização. Não temos prédios em condições, nem um, ao menos. Não temos tido material didático que baste às nossas necessidades. Nem, técnicos em investigações sobre rendimento escolar. Nem professores especializados em orientação de ensino. Nem sequer professores em quantidades suficientes para suprir as necessidades de nossas escolas. [...] Embora todas as nossas deficiências, a custa de sacrifícios, de renúncias e de boa vontade, os que se dedicam ao magistério, nesta terra, aprenderam a fazer milagres. [...] (LINS, 1947, p.4)
\end{abstract}

Nesse cenário dinâmico de novas formas de organização política, geográfica, populacional e educacional com a criação do Território, chama-nos a atenção os professores que "aprenderam a fazer milagres" diante da carência de formação, de materiais didáticos e estruturas físicas adequadas ao ensino. Em outro artigo, o autor sai em defesa da criação de um Curso Normal mantido pelos cofres públicos, pois já existiam duas escolas confessionais particulares: O Colégio Dom Bosco e o Instituto Maria Auxiliadora ${ }^{4}$, sendo esta dedicada a formação de mulheres:

\footnotetext{
${ }^{2}$ Em 1945 passou a se chamar Divisão de Educação e um novo regimento foi aprovado em 1948 (GOMES, 2007).

${ }^{3}$ De acordo com dados do Serviço de Estatística e Cultura publicada na Biblioteca do IBGE (sem data).

${ }^{4}$ Os colégios Dom Bosco e Maria Auxiliadora são instituições particulares administradas pela ordem religiosa dos Salesianos. Foram criados, respectivamente, em 1932 e 1933, sendo o primeiro destinado à educação dos meninos e o segundo, à das meninas. Em 1945 as duas instituições começaram a ofertar os primeiros cursos ginasiais (SILVA, 1991; GOMES, 2007). Em 1937 as Salesianas Filhas de Maria Auxiliadora começaram oferecer um curso de formação para professoras normalistas rurais, criado pelo
} 
[...] há ainda um imperativo irrecorrível da Lei: as organizações particulares, religiosas inclusive, não podem manter Institutos de Educação; só o Governo tem essa liberdade. Ora, o Guaporé, em futuro próximo, será obrigado, pelas contingencias, a ter esse tipo de educandário. (JORNAL ALTO MADEIRA, 15/07/1948, edição 03215, p.2).

Nesse sentido, este artigo tem como intuito trazer a lume a formação de regentes de ensino primário do Guaporé, de iniciativa pública, no Curso Normal Regional "Carmela Dutra", criado por meio do Decreto n. 47 de 19 de dezembro de 1947. Para tanto, foram utilizados documentos oficiais referentes à formação de professores primários, obras memorialísticas, jornais de publicação local e, a pesquisa de Pascoal de Aguiar Gomes (2007). O recorte temporal delimitado compreende o ano inicial de criação do Curso (1947) e o ano de conclusão da primeira turma de formandos em 1951.

Está fundamentado na investigação dos detalhes percorrendo as "pistas", "sinais" ou "indícios", utilizando como ferramenta de pesquisa o método indiciário (GINZBURG, 1989) por se constituir como uma forma de juntar dados de diferentes origens que se mostram reveladores dos fenômenos de uma determinada realidade que está repleta de particularidades.

\section{O Curso Normal Regional do Território Federal do Guaporé}

O Curso Normal Regional "Carmela Dutra" (CNRCD) do Território Federal do Guaporé foi criado pelo Decreto n. 47 de 19 de dezembro de 1947, expedido pelo governador Frederico Trotta ${ }^{5}$, visando atender o $1^{\circ}$ Ciclo do Ensino Normal. Conforme a Lei Orgânica do Ensino Normal (Decreto 8.530 de 1946), cabia ao $1^{\circ}$ Ciclo oferecer o curso de regentes de ensino primário em 4 anos $\left(\mathrm{Art}^{\circ}{ }^{\circ}\right)$. Ao adotar a nomenclatura de "Curso Normal Regional", já estava implícito a oferta do primeiro ciclo, conforme determinado pela Lei Orgânica (Art. $5^{\circ}$ ).

Inicialmente, o CNRCD não contava com prédio próprio, funcionando nas dependências do Grupo Escolar Duque de Caxias, em Porto Velho. No ano seguinte de sua instalação, o jornal Alto Madeira (13/03/1949, edição n.03345, p.1) publicou juntamente com o reconhecimento do Curso pelo INEP $^{6}$, a liberação de um recurso de [...] 500 mil cruzeiros para a construção do respectivo edifício, dentro da verba de 2 milhões já programados. [...]". Sendo "[...] escolhido o terreno para a Escola Normal, junto ao Grupo Duque de Caxias. [...]”, próximo de onde já estava funcionando.

Sendo assim, o prédio foi construído em três alas de dois pavimentos. Contava com 12 salas de aulas, laboratórios de Geografia, Ciências, Desenho, Trabalhos Manuais, Diretoria, Secretaria, biblioteca, Sala dos professores e um Auditório, todos devidamente equipados para seu funcionamento. Contava também, com água encanada, iluminação elétrica, 12 banheiros e vestuário. "Possuía todo material necessário às aulas de Educação Física, bem como aparelhos e utensílios indispensáveis a um Gabinete

Governador do Amazonas, pois na época Porto Velho pertencia aquele estado, e funcionou até 1946 (Cf. dissertação de PRADO, 2017, que analisa o percurso de criação e implantação da Escola Normal Rural Nossa Senhora Auxiliadora - ENRA).

${ }^{5}$ Nove (9) diferentes homens governaram o Território Federal do Guaporé. Frederico Trotta foi o terceiro gestor territorial, cuja nomeação foi feita pelo então Presidente da República Eurico Gaspar Dutra em 31/10/1947, permanecendo até 09/06/1948.

${ }^{6}$ Instituto Nacional de Estudos e Pesquisas. 
Médico-Biométrico" (GOMES, 2007, p.132). Mesmo que a primeira turma não tivesse usufruído dessa estrutura física e material, a sua construção e organização apontava para uma preocupação em atender ao que estava definido pela Lei Orgânica, referente à metodologia de ensino.

O Curso destinava-se a alunos de ambos os sexos na faixa etária de 13 a 25 anos, com comprovada sanidade física e mental, brasileiro (a), "[...] ausência de defeito físico ou distúrbio funcional que contraindique o exercício da função docente, bom comportamento social e habilitação nos exames de admissão". (BRASIL, Decreto-Lei n. 8.530, 1946, Art. 20).

A Divisão de Educação circulou no periódico Alto Madeira as instruções estabelecendo as normas para a realização dos exames de admissão ao referido Curso. $\mathrm{O}$ documento determinava o dia e o local de realização das provas, sua tipologia, tempo, pontuação, composição da banca examinadora, julgamento das provas e condições para aprovação/habilitação dos candidatos.

\section{Divisão de Educação \\ Instruções para a realização dos exames ao curso de admissão da Escola Normal "Carmela Dutra"}

O DIRETOR DA DIVISÃO DE EDUCAÇÃO devidamente autorizado pelo Exmo. Snr. Governador do Território.

RESOLVE expedir as seguintes Instruções para os exames de admissão ao Curso Normal Regional "Carmela Dutra" no ano de 1948.

\section{I - DAS PROVAS}

Art. $1^{\circ}$ - As provas serão realizadas na sede da Divisão de educação, no dia 18 do corrente às $8: 30$ horas da manhã.

Art. $2^{\circ}$ - Os exames constarão de provas escritas e orais de Português, Matemática, Geografia e História do Brasil.

Parág. $1^{\circ}$ - As provas escritas, de caráter eliminatório serão de:

a) - Português.

b) - Matemática.

Parág. $2^{\circ}$ - As provas orais constarão de Português, Matemática, Geografia e História do Brasil.

Art. $3^{\circ}$ - Haverá no máximo, um prazo de sessenta minutos para a realização da prova de Linguagem e de noventa minutos para a de Matemática.

Art. $4^{\circ}$ - Para garantia de anonimato no julgamento das provas, escritas, as folhas fornecidas aos candidatos terão apenas talões de identificação, que serão rubricados pelo presidente e por um dos examinadores.

Parág. único - Esses talões serão destacados na presença da comissão examinadora (ilegível) após a terminação da prova ficarão encerrados em invólucros fechados até a conclusão do julgamento respectivo.

Art. $5^{\circ}$ - O recolhimento das provas obedecerá as seguintes normas:

a) Terminada a prova, cada candidato deverá permanecer sentado até que a mesma seja recolhida. Proceder-se-á, então, a chamada para o candidato assinar a parte da prova que vai ser destacada, encerrando-a no envelope que lhe será entregue na ocasião.

Art. $6^{\circ}$ - Nas provas orais cada examinador deverá arguir o candidato durante $10(\mathrm{dez})$ minutos.

Art. $7^{\circ}$ - Os pontos para a provas orais serão em número de 10 (dez) para cada disciplina, organizados igualmente de acordo com os programas já publicados. 


\section{II - DAS COMISSÕES EXAMINADORAS}

Art. $8^{\circ}$ - As bancas examinadoras serão organizadas pela Divisão de Educação.

\section{III - DO JULGAMENTO DAS PROVAS E DA HABILITAÇÃO DOS}

\section{CANDIDATOS}

Art. $9^{\circ}$ - O julgamento das provas será feito seguindo a quantidade, exatidão e perfeição do trabalho do candidato, aferido esse trabalho, por graduação de 0 a 100 pontos, sendo aproveitadas as frações até décimos.

Art. $10^{\circ}$ - No julgamento da prova escrita de Português, a banca examinadora atribuirá 80 (oitenta) pontos a parte de redação e 20 (vinte) pontos a parte do ditado.

Art. $11^{\circ}$ - No julgamento das provas orais, a banca examinadora observará sempre a graduação de 0 a 100 pontos para cada matéria.

Art. $12^{\circ}$ - O julgamento final será feito da seguinte forma: a média da prova escrita mais a média da prova oral divididas por 2.

Parág. Único - No cálculo das médias serão consideradas as frações até décimos.

Art. $13^{\circ}$ - Será considerado não aprovado no exame de admissão o candidato que:

a) obtiver grau inferior a 50 (cincoenta), em qualquer das provas escritas.

b) obtiver média geral inferior a 50 (cincoenta).

c) utilizar meios ilícitos para a solução das questões ou desrespeitar as bancas examinadoras ou as prescrições por essas estabelecidas para realização das provas.

\section{IV - DISPOSIÇÕES GERAIS}

Art.14 $4^{\circ}$ - $\mathrm{O}$ candidato inscrito no exame fica sujeito às condições estabelecidas nestas Instruções.

Art. $15^{\circ}$ - Terminados os trabalhos dos exames, a Divisão de Educação publicará a classificação dos aprovados gerais em ordem decrescente das médias gerais obtidas.

Porto Velho, 16 de março de 1948.

$$
\text { LAUDIMIA TROTTA }
$$

Diretora da D. de Educação (JORNAL ALTO MADEIRA, 13/03/1948, edição 03178, p. 4)

A relação de aprovados no referido exame de admissão ao Curso Normal Regional "Carmela Dutra" foi divulgada alguns dias depois na edição n.03181 do Jornal Alto Madeira (28/03/1948, p.4) constando da lista um total de trinta e seis nomes, sendo sete (7) homens e vinte e nove (29) mulheres, conforme transcrito abaixo:

1 - Luiz Alves Santana; 2 - Antonio Augusto Vasca; 3 - Ivette Strutos Arouca; 4 - Flayza Maria Arouca; 5 - Marlene Costa; 6 - Angelina dos Anjos; 7 - Lady Alves Corrêa; 8 - Lourival Chagas da Silva; 9 - Eunice de Oliveira Monteiro; 10 - Aglacy Lins Lobo da Silva; 11 - Norma Iracema Jacob; 12 - Samuel Monteiro dos Santos; 13 - Maria Smith Campelo; 14 Maria Rodrigues da Costa; 15 - Graziela Soeiro; 16 - Maria Perpetuo Socorro M. de Araújo 17 - Rosa Maria Dias de Carvalho; 18 - Judith Holder; 19 - Maria Neuza Freire Rivoredo; 20 - Noêmia Arantes Meira; 21 - Herbert Alencar de Souza; 22 - Gabriela Pereira de Souza; 23 - Iracema Costa; 24 Albertina Coelho; 25 - Neuza Alves Carneiro; 26 - Sebastiana Gomes de Oliveira; 27 - Eliza Alves de Lima; 28 - Joselina da Conceição R. Santos; 29 - Raimundo Pinheiro Albano; 30 - Mosa Terezinha Carneiro; 31 - Lídia dos Anjos; 32 - Geny Ferreira de Mendonça; 33 - Neuza Felix do Nascimento; 34 - Maria Rosa Pinheiro; 35 - Clarisse de Oliveira Messias; 36 - Jeremias de Oliveira Lobato. 
Apesar de o Curso Normal Regional funcionar sob o regime de externato misto, o percentual de aprovados reafirma ser o curso de formação de professores um espaço eminentemente feminino ${ }^{7}$, com já apontado por vários autores. Nesse sentido, o Curso funcionou também em regime de internato, porém, "para as moças que residem no interior" (JORNAL ALTO MADEIRA, 15/04/1948, edição 03186, p.2). Na figura (1) abaixo se encontra os alunos da referida primeira turma do CNRCD acompanhados da diretora de Educação, na época, Laudimia Trotta (GOMES, 2007):

Figura $1-1^{\mathrm{a}}$ Turma do Curso Normal Regional "Carmela Dutra"

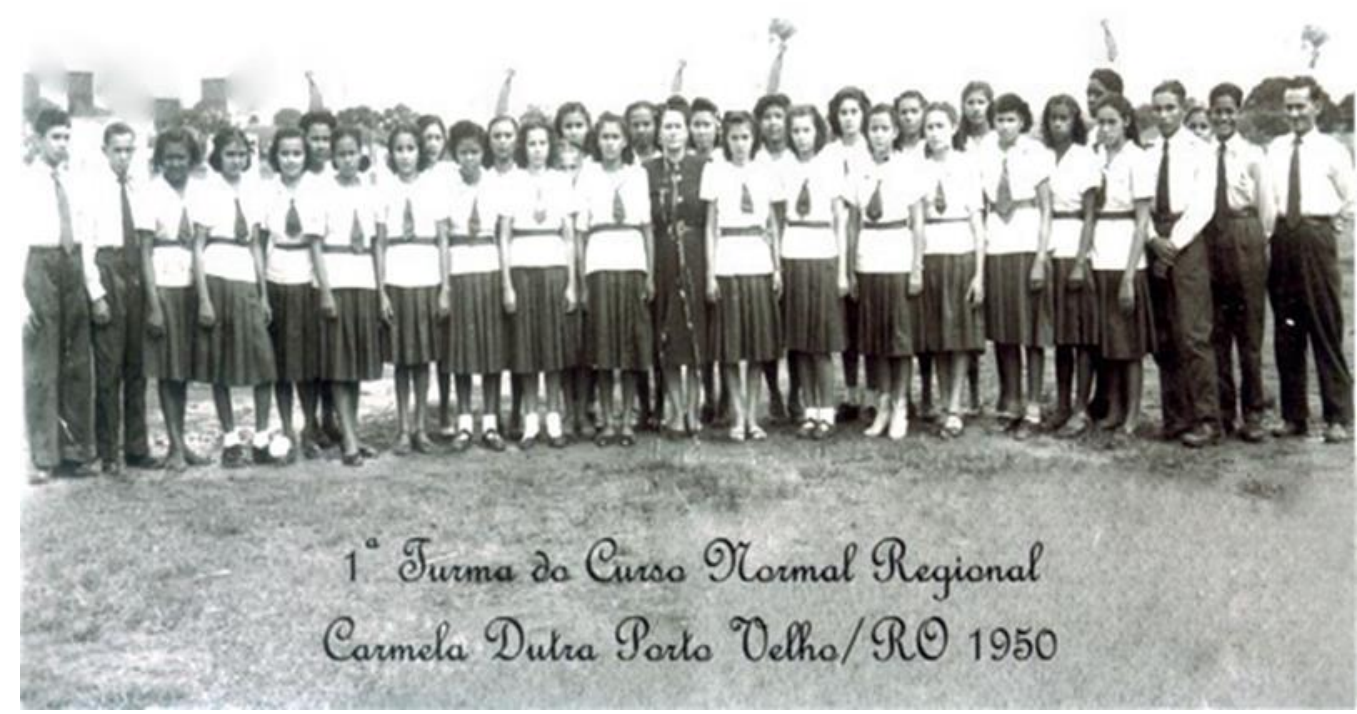

Fonte: Mario Nobre (2020).

Os alunos dessa primeira turma do CNRCD cursaram no ano de 1949 as seguintes disciplinas:

Foram reiniciados desde março último os trabalhos escolares do Curso Normal Regional "Carmela Dutra", dotando-se elevada matrícula e acréscimo de uma $3^{\mathrm{a}}$ série. Para as diversas cadeiras do referido Curso foram designados os seguintes professores:

Prof. Marise Castiel - Português na $1^{\text {a }}$ série;

Prof. Floripes Carvalho - Corte e costura nas $1^{\mathrm{a}}, 2^{\mathrm{a}}$ e $3^{\mathrm{a}}$ séries;

Prof. Maria do Carmo Ribeiro - Trabalhos Manuais nas $1^{\mathrm{a}}, 2^{\mathrm{a}}$ e $3^{\mathrm{a}}$ séries;

Prof. Cléa Bringel Guerra - Educação Física nas $1^{\mathrm{a}}, 2^{\mathrm{a}}$ e $3^{\mathrm{a}}$ séries;

Prof. Henrique Fiorani - Canto Orfeônico nas $1^{\mathrm{a}}, 2^{\mathrm{a}}$ e $3^{\mathrm{a}}$ séries;

Prof. José Bezerra Duarte - Português na $3^{\mathrm{a}}$ série e Geografia na $1^{\mathrm{a}}$;

Prof. Enos Eduardo Lins - Matemática na $1^{\mathrm{a}}$ série e Português na $2^{\mathrm{a}}$;

Dr. Ernesto Almeida - Ciências Naturais nas $1^{\mathrm{a}}$ e $2^{\mathrm{a}}$ séries;

Prof. Carlos Sales Vieira - Desenho nas $1^{\mathrm{a}}$ e $2^{\mathrm{a}}$ séries;

Prof. Osório B. Serra - História Geral na $3^{\mathrm{a}}$ série;

Eng. José Otino Freitas - Desenho na $3^{\mathrm{a}}$. Série;

Dr. Ari Tupinambá Pinheiro - Anatomia e Matemática na $3^{\mathrm{a}}$ série. (JORNAL ALTO MADEIRA, 08/04/1949, edição n.03355, p. 4).

\footnotetext{
${ }^{7}$ Cf. Tanuri (2000); Almeida (1998; 2006) entre outros.
} 
O corpo docente do CNRCD era formado por professores e profissionais de diversas áreas e, de acordo com Gomes (2007), todos estavam devidamente registrados no Ministério da Educação, mas muitos não tinham a formação adequada para o exercício do magistério, eram servidores do Governo do Território que atuavam em outras áreas.

A partir da publicação acima é possível inferir que a organização didática do Curso Normal Regional do Guaporé contava com doze (12) professores no ano de 1949, no qual predominavam disciplinas de caráter propedêutico como: português, matemática, geografia, história geral e do Brasil e ciências naturais, atendendo assim o que prescrevia o artigo $7^{\circ}$ da Lei Orgânica do Ensino Normal.

A respeito do currículo, a "Exposição de motivos", n.155 do Ministro da Educação e Saúde, relativa à Lei Orgânica do Ensino Normal estabelecia:

[...] o currículo mínimo e conveniente seriação de disciplinas, admitindo-se no entanto, maior enriquecimento dos estudos, onde isso seja possível. Todas as demais normas de organização estão baseadas em igual princípio de flexibilidade, a fim de que, sem quebra de coordenação nacional necessária, possa ter o ensino normal nos seus vários tipos estaduais todas as possibilidades de constante aperfeiçoamento. (BRASIL, 1946, p.274-275).

No entanto, de acordo com Tanuri (2000, p. 18), o currículo do curso de primeiro ciclo:

[...] incorria nas velhas falhas que motivaram críticas às escolas normais, ou seja, contemplava predominantemente disciplinas de cultura geral, restringindo a formação profissional tão somente à presença de duas disciplinas na série final: psicologia e pedagogia, bem como didática e prática de ensino.

No tocante as disciplinas: "Didática" e "Prática de Ensino", que deveriam ser ministradas na quarta série do Curso Regional, o Governo Territorial do Guaporé publicou um Decreto n.263 que concedia prêmios aos alunos do Curso Normal Regional "Carmela Dutra", por considerar que competia ao "[...] Estado promover meios de estímulo à juventude escolar para que se dedique aos estudos com interesse crescente, premiando, bem assim, os melhores e mais aplicados alunos" (JORNAL ALTO MADEIRA, 05/09/1953, edição n.04347, p.3).

A referida premiação seria concedida a alunos finalistas do Curso Normal Regional, sendo o primeiro prêmio: "[...] ao quartanista que obtiver a maior nota final na cadeira de Didática e Prática de Ensino"; e, o segundo prêmio "[...] ao quartanista que obtiver, no computo final dos graus de aprovação anuais, a maior média como nota final do curso". (Idem).

A prática de ensino seria feita, de acordo com a Lei Orgânica do Ensino Normal $(1946$, art.14, d): “[...] em exercícios de observação e de participação real no trabalho docente, de tal modo que nela se integrem os conhecimentos teóricos e técnicos de todo o curso". Ainda, conforme tal legislação, "todos os estabelecimentos de ensino normal manterão escolas primárias anexas para demonstração e prática de ensino", e, "cada 
curso normal regional deverá manter, pelo menos, duas escolas primárias isoladas" (Art. 47, § 1. ${ }^{\circ}$, p.285). No caso da Escola Normal Regional do Guaporé, as duas escolas isoladas eram: Samaritana, localizada no Bairro Olaria, e Frederico Trotta, no Bairro do $\mathrm{km} 1$ da rodovia (GOMES, 2007, p.123-124). Mas, não foi possível localizar durante esta pesquisa, indícios da aplicação desta normativa nas referidas escolas isoladas.

A Colação de Grau da primeira turma do Curso Normal Regional "Carmela Dutra" ocorreu no Auditório da Divisão de Educação no dia 21 de dezembro de 1951, conforme convite que circulou no jornal Alto Madeira (13/12/1951, edição n.03870, p. 4) e, aos concluintes foram expedidos certificados de Regentes do Ensino Primário.

Em 1952, no mesmo prédio, passou a funcionar a Escola Normal, que de acordo com a Lei Orgânica do Ensino Normal (1946, p. 277) "será o estabelecimento destinado a dar o curso de segundo ciclo desse ensino, e ciclo ginasial do ensino secundário" (1946, p. 99, art. $2^{\circ}$ ) voltado para a "formação de professores primários", com estudos de três anos após a conclusão do curso de regentes, ou após a conclusão do $1^{\circ}$ ciclo do curso secundário geral, permitindo-se ainda o funcionamento do curso em dois anos de estudos intensivos.

\section{CONSIDERAÇÕES FINAIS}

Em 1950 o Território Federal do Guaporé contava com 90 unidades escolares de ensino primário, dos quais 70 localizados no município de Porto Velho ${ }^{8}$. Frente a este número de escolas primárias espalhadas por toda região, a formação dos Regentes do Ensino Primário, diplomados pela Escola Normal Regional "Carmela Dutra" teve um impacto positivo, pois possibilitou atender as demandas necessárias, suprindo uma lacuna existe tanto no aspecto quantitativo quanto no da formação dos professores leigos existentes na época.

Muitos dos alunos egressos da primeira turma do Curso Normal Regional passaram a atuar como Professores do Ensino Primário nas mais diferentes escolas do Guaporé ${ }^{9}$ como: Lourival Chagas da Silva (1955) na Escola Rural "Frederico Trotta"; Gabriela Pereira de Souza (1955) no Grupo Escolar "Barão do Solimões"; Herbert Alencar de Souza (1955) inspetor das escolas primárias da capital e do interior; Neuza Alves Carneiro (1955) nomeada interinamente para o quadro de funcionários; Maria Rodrigues da Costa (1955) nomeada para Comissão Examinadora de aplicação de provas no Grupo Escolar.

Apesar de várias críticas terem sido produzidos por pesquisadores e intelectuais a partir da década de 1950 e anos subsequentes, no tocante ao currículo do Curso Normal Regional, que diplomava os mestres primários com uma formação considerada menos complexa, foi a partir da criação deste curso no Território Federal do Guaporé que se consolidou a oferta do Ensino Normal público na região, de relevância educacional e enquanto instituição formadora do magistério para atender as demandas frequentes das escolas primárias, que também se encontravam em processo de expansão e, a maioria, localizava-se nos mais longínquos recantos do território.

\footnotetext{
${ }^{8}$ IBGE. Território do Guaporé, s/d.

${ }^{9}$ Publicados nos Atos Oficiais (designação, nomeação ou remoção) em diferentes edições do Jornal Alto Madeira.
} 


\section{REFERÊNCIAS}

ALMEIDA, Jane Soares de. Mulher e educação: a paixão pelo possível. São Paulo: UNESP, 1998.

Mulheres na educação: missão, vocação e destino? A feminização do magistério ao longo do século XX. In: SAVIANI, D.; ALMEIDA, J. S. d.; SOUZA, R. F. d.; VALDEMARIN, V. T. (Eds.). O legado educacional do século XIX. 2. ed. São Paulo: Editora Autores Associados, 2006.

BRASIL. Decreto-Lei n. ${ }^{\circ}$ 8.530, de 2 de janeiro de 1946. Lei Orgânica do Ensino Normal. Revista Brasileira de Estudos Pedagógicos On-line, Brasília, v.7, n. 20, p.73287, fev.1946.

GINZBURG, Carlo. Mitos, emblemas, sinais: morfologia e história. - São Paulo: Cia. das letras, 1989.

GOMES, Pascoal de Aguiar. A educação escolar no Território Federal do Guaporé (1943-1956). 2007. Mato Grosso: 152 f. Dissertação (Mestrado) - Pós-Graduação em Educação. Universidade Federal de Mato Grosso, Cuiabá, 2007.

HUGO, Vitor. Cinquenta anos do Território Federal do Guaporé. 4.ed. Porto Velho: abg gráfica, 1995.

IBGE. Território do Guaporé. Disponível em:

$<$ https://biblioteca.ibge.gov.br/visualizacao/periodicos/113/col_mono_n3_territoriorond onia.pdf>. Acesso em: 20/04/2020.

JORNAL ALTO MADEIRA. Porto velho, n. 03186, p.2, 15/04/1948. Disponível no Acervo Biblioteca Nacional Digital:

$<$ http://memoria.bn.br/DocReader/DocReader.aspx $? \mathrm{bib}=060160 \&$ Pasta $=\& P e s q=a l t o \% 2$ Omadeira>. Acesso em set.2018.

JORNAL ALTO MADEIRA. Porto velho, n. 03215, p.2, 15/07/1948. Disponível no Acervo Biblioteca Nacional Digital:

$<$ http://memoria.bn.br/DocReader/DocReader.aspx $? \mathrm{bib}=060160 \&$ Pasta $=\& P e s q=a l t o \% 2$ 0madeira>. Acesso em set.2018.

JORNAL ALTO MADEIRA. Porto velho, n. 03345, p.1, 13/03/1949. Disponível no Acervo Biblioteca Nacional Digital:

$<$ http://memoria.bn.br/DocReader/DocReader.aspx ?bib=060160\&Pasta=\&Pesq=alto\%2 0madeira>. Acesso em set.2018.

JORNAL ALTO MADEIRA. Porto velho, n. 03355, p.4, 08/04/1949. Disponível no Acervo Biblioteca Nacional Digital:

$<$ http://memoria.bn.br/DocReader/DocReader.aspx $? \mathrm{bib}=060160 \&$ Pasta $=\&$ Pesq $=$ alto $\% 2$ Omadeira>. Acesso em set.2018.

JORNAL ALTO MADEIRA. Porto velho, n. 03870, p.4, 13/12/1951. Disponível no Acervo Biblioteca Nacional Digital:

$<$ http://memoria.bn.br/DocReader/DocReader.aspx $? \mathrm{bib}=060160 \&$ Pasta $=\& P e s q=a l t o \% 2$ 0madeira>. Acesso em set.2018. 
JORNAL ALTO MADEIRA. Porto velho, n. 04871, p.4, 26/05/1955. Disponível no Acervo Biblioteca Nacional Digital:

<http://memoria.bn.br/DocReader/DocReader.aspx $? \mathrm{bib}=060160 \&$ Pasta $=\& P e s q=a l t o \% 2$ Omadeira>. Acesso em set.2018.

JORNAL ALTO MADEIRA. Porto velho, n.03181, p.4, 28/03/1948. Disponível no Acervo Biblioteca Nacional Digital:

$<$ http://memoria.bn.br/DocReader/DocReader.aspx $? \mathrm{bib}=060160 \&$ Pasta $=\& P e s q=a l t o \% 2$ Omadeira>. Acesso em set.2018.

LINS, Enos Eduardo. Problemas educacionais: Deve existir o curso Normal Regional “Carmela Dutra”. Jornal Alto Madeira, Porto Velho, n. 03215, p.2, 15/07/1948.

. Situação do ensino em Porto Velho. Jornal Alto Madeira, Porto Velho, n. 03088, p.4, 01/05/1947.

NOBRE, Mário. $1^{a}$ Turma do Curso Normal Regional: Colégio Normal Carmela Dutra (Porto Velho no ano de 1950). Cuiabá, 16 abr. 2020. Facebook: marionobre. Disponível em:

$<$ https://www.facebook.com/photo?fbid=2206838929417857\&set=gm. 2376629659114 860>. Acesso em: 16 abr. 2020.

PRADO, Fernanda Batista do. Entre o oratório e a profissão: formação de professoras na Escola Normal Rural Nossa Senhora Auxiliadora em Porto Velho/RO (1930-1946). 2017. 157 f. Dissertação (Mestrado em Educação) - Programa de Pós-graduação em Educação, Universidade Federal de Mato Grosso, Cuiabá, 2017.

SILVA, Amizael Gomes da. Amazônia: Porto Velho. Porto Velho: Palmares, 1991.

TANURI, Leonor Maria. Revista Brasileira de Educação On-line, Rio de Janeiro, n. 14, p.1-35, maio/ago. 2000.

TERRITÓRIO FEDERAL DO GUAPORÉ. Decreto n. 47 de 19 de dezembro de 1947. Cria o Curso Normal Regional do Território Federal do Guaporé. Governo Territorial, 1947.

Recebido em: 28/02/2019

Aprovado em: 26/04/2019 